\title{
Single Session, Multiple Band Ligation for Haemorrhoids
}

\author{
K. Alubaidi*, G. Clarke, A. Jamil, E. Ghareeb \\ South West Acute Hospital, Enniskillen, UK \\ Email: *k.alubaidi@nhs.net
}

Received 28 March 2016; accepted 9 May 2016; published 12 May 2016

Copyright (C) 2016 by authors and Scientific Research Publishing Inc.

This work is licensed under the Creative Commons Attribution International License (CC BY). http://creativecommons.org/licenses/by/4.0/

(c) $\underset{\mathrm{EY}}{\mathrm{Br}}$ Open Access

\begin{abstract}
Background: Single session, multiple Band Ligations (BL) for haemorrhoids has been practised in the UK for more than 40 years. It has been claimed that multiple BL in a single session can cause pain and discomfort [1]-[3], although this issue has not been formally assessed in the past. Our study was designed to examine this claim. Methods: Patients were randomly chosen for this study from rectal bleeding clinics and endoscopy lists. On diagnosis of haemorrhoids at proctoscopy these patients were offered, and treated with multiple BL. Results: 50 patients were treated with BL for $2^{\text {nd }}$ and (the majority) $3^{\text {rd }}$ degree haemorrhoids. All patients needed $2-3$ haemorrhoids banded. $76 \%$ stated that they had no pain or discomfort, $14 \%$ complained of slight pain and $10 \%$ complained of very slight discomfort. $90 \%$ were successfully treated, and $97 \%$ stated that they would be prepared to undergo further treatment if necessary. Conclusion: Single session multiple haemorrhoids band ligations are a safe procedure which can be performed by surgeons in outpatient clinics with minimal discomfort for patients.
\end{abstract}

\section{Keywords}

Haemorhoids, Ligation, Single Session

\section{Introduction}

Barron Dublin introduced BL in the early nineteen-sixties [2]. It has proved to be the most successful, nonoperative method of treating $1^{\text {st }}, 2^{\text {nd }}$ and $3^{\text {rd }}$ degree haemorrhoids [2]. $4^{\text {th }}$ degree haemorrhoids should be treated surgically [1]. The success rate for BL reaches $78 \%$ of cases, the remaining $22 \%$ requiring further BL [2].

In the past the procedure was more difficult because of the equipment required. Two people were necessarythe operator to apply the bands, and the $2^{\text {nd }}$ person holding the proctoscope. The operator needed 2 instruments:

\footnotetext{
"Corresponding author.
} 
one to draw the tissue, and the other to fire the band. Reloading with bands was required after each application to each haemorrhoid [1] — this was awkward and time-consuming.

Equipment was developed which used suction to draw the tissue, so the operator could use one hand to hold the proctoscope, and the other to apply the suction and fire the band. However, the problem of repeatedly having to stretch and load rubber bands onto the instrument's firing mechanism continued to be difficult; the time spent on this, while the patient had the scope repeatedly reinserted, resulted in some operators recommending the application of only one band in a single session [3].

The recent introduction of equipment which can fire multiple bands automatically without the need to reload has overcome this problem, making the procedure easier, quicker and more comfortable, and allows more precise band application.

\section{Patients and Methods}

Fifty patients were chosen randomly through our rectal bleeding clinics or endoscopy lists. All patients had rigid or flexible sigmoidoscopy or colonoscopy, according to our protocol for rectal bleeding clinics (designed using various national accepted guidelines), and proctoscopy. $1^{\text {st }}, 2^{\text {nd }}$ and $3^{\text {rd }}$ degree haemorrhoids were banded using the Haemoband (price £19-Haemoband Surgical Ltd.), which holds 4 latex-free rubber bands on its firing mechanism.

During the procedure the bands were applied to the neck of each haemorrhoid and enough tissue (2 - $4 \mathrm{~mm})$ was included to hold the band in place. The necrosis and tissue reaction from the band produces a fibrous tissue reaction, which retracts the redundant, prolapsed mucosa and glues it to the rectal wall. This also reduces the size of the venous plexus in the haemorrhoid tissue.

A protocol was devised to record the presenting symptoms, procedure time, number of haemorrhoids and their degree, the number of rubber bands applied and the level of the patient's discomfort or pain during and just after the procedure. Patients were followed up either in the surgical outpatient clinic or contacted by phone to complete the protocol form. They were asked if they were completely improved (to extent that they required no further treatment), slightly improved or if there was no improvement. They were also asked that if they were to need any similar treatment in the future, would they agree to this again, or not.

The total number of patients was 50 (24 males), ranging from 18 to 79 years. The duration of symptoms varied from 4 months to 15 years. Twenty patients complained of chronic constipation, and 2 females associated their haemorrhoids with pregnancy.

Four patients had 2 haemorrhoids and 46 had 3 haemorrhoids.

Forty eight patients complained of bright red PR bleeding, 10 of perineal irritation, 2 of associated anal pain, and 8 patients complained of mucus secretions PR (Figure 1).

Forty six patients had 3 rubber bands applied during the same session, and 4 patients had 2 bands applied. Forty eight procedures took less than 2 minutes, one took 2 - 4 minutes and one 4 - 6 minutes.

\section{Results}

Seven patients complained of slight pain during the procedure and 4 patients complained of very slight pain, 39 did not complain, on asking, of any pain or discomfort (Figure 2).

Five patients (10\%) said that there was no change in their symptoms (PR bleeding and mucus) 6 weeks after treatment, and 45 said that they had completely improved and had no symptoms; thus a cure rate of $90 \%$. All

Patients Presentation

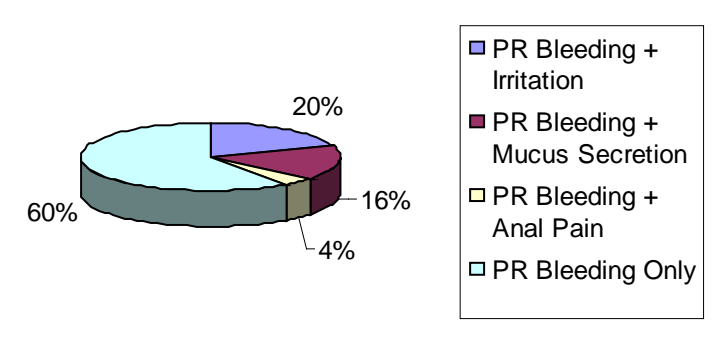

Figure 1. Patients presentation. 
patients with perianal irritation improved. No patient had continued pain or discomfort after the procedure (even those who had slight or very slight pain during the procedure) (Figure 3).

When asked if they would have the procedure repeated, 47 answered "Yes" and 3 "No". There were no complications recorded from these patients.

\section{Discussion}

Haemorrhoids are one of the most common surgical diseases [1]. It is estimated that it will affect $50 \%-60 \%$ of the population of the United States at some stage in their life [4]-[7]. They equally affect different races and both genders. Chronic constipation, pregnancy [1] and even the erect human position are thought to be contributing factors in their aetiology [2] [8]. Haemorrhoids are merely prolapsed mucosa, which covers congested venous plexuses [2]. The later are normally present in the anus above the dentate line and are supposed to play an important role in anal continence.

BL has been in practice for over 40 years, and has proved to be one of the most effective methods for treating $1^{\text {st }}, 2^{\text {nd }}$ and $3^{\text {rd }}$ degree haemorrhoids [2]. The problem with this method of treatment has always been the difficulty of its application. This has resulted in the introduction of other treatment methods, such as cryosurgery, laser treatment, infrared coagulation and radiofrequency coagulation [9]-[11]. Some claim the same success rate as BL, but have required several outpatient sessions to apply the treatment [3] [9]-[11].

With the introduction of new devices for BL, this method has continued to be the most popular and cost effective method of treatment. There has long been debate around the best approach for using BL. Some authors suggested treating one haemorrhoid with BL at one time to avoid patient discomfort [3]. In our opinion, this reflects the difficulty in reloading the bands, and may relate to how health care is provided in certain countries.

We used an instrument which does not require reloading, and hence the procedure's time and the patient's discomfort are both significantly decreased. Our results are better than the previously published for this method [2]: we believe this reflects better control of firing the bands, whilst the patient is fully relaxed with minimal or no discomfort.

For $3^{\text {rd }}$ degree haemorrhoids other surgical procedures have been recommended by some authors, including stapled haemorrhoidectomy; however, these can require hospital admission, and can be associated with pain and necrosis of the rectal mucosa [12]-[18]. The absence of any complications in our own study reflects the relative safety of the technique of multiple BL; complications such as bleeding or perineal sepsis occur only in a very small number of patients [19]-[22].

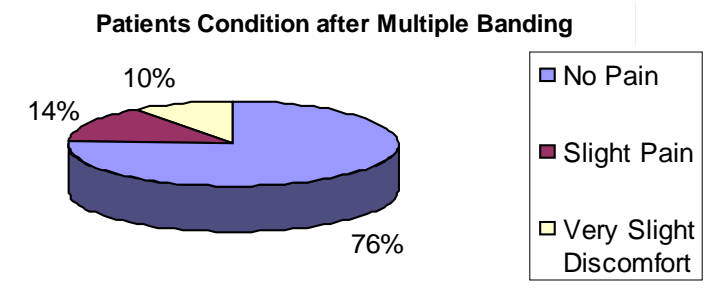

Figure 2. Patients condition after multiple banding.

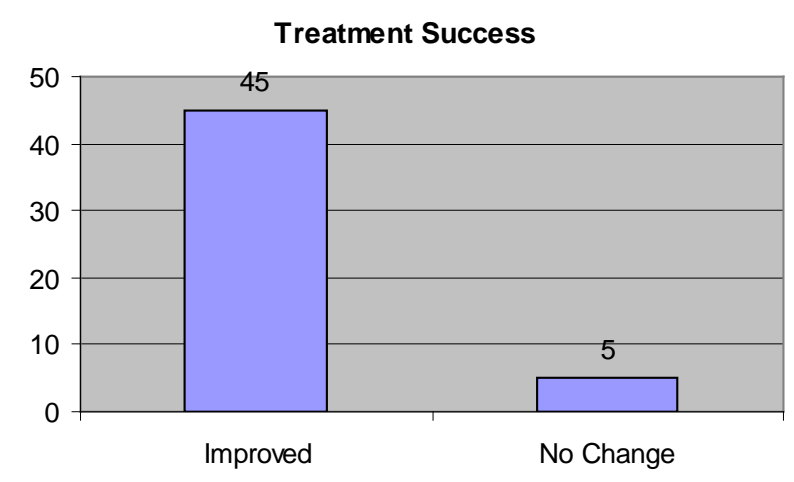

Figure 3. Treatment success. 


\section{Conclusion}

From this study we can say that banding multiple haemorrhoids using the Haemoband is a safe \& cost effective procedure which can be performed in the surgical outpatient clinic with no anaesthesia \& with minimal or no discomfort.

\section{Declaration of Interest}

Mr. E. Ghareeb developed the Haemoband.

\section{References}

[1] Barron, J. (1963) Office Ligation of Internal Haemorrhoids. American Journal of Surgery, 105, 563-673. http://dx.doi.org/10.1016/0002-9610(63)90332-5

[2] Finninger, P. (1997) Modern Treatment for Internal Haemorrhoids. BMJ, 314, 1211. http://dx.doi.org/10.1136/bmj.314.7089.1211

[3] Dennison, A., Whiston, R.J., Rooney, S., Chadderton, R.D., Wherry, D.C. and Morris, D.L. (1990) A Randomised Comparison of Infrared Photocoagulation with Bipolar Diathermy for Outpatient Treatment of Haemorrhoids. Diseases of the Colon \& Rectum, 33, 32-34. http://dx.doi.org/10.1007/BF02053198

[4] Yang, R., Migikovsky, B., Peicher, J. and Laine, L. (1993) Randomised, Prospective Trial of Direct Current versus Bipolar Electro Coagulation for Bleeding Internal Haemorrhoids. Gastrointestinal Endoscopy, 39, 766-769. http://dx.doi.org/10.1016/S0016-5107(93)70261-8

[5] Corman, M.L. (1998) Colon and Rectal Surgery. 4th Edition, Lippincott-Raven, Philadelphia, 147-205.

[6] Salvati, E.P. (1999) Non-Operative Management of Haemorrhoids. Diseases of the Colon \& Rectum, 42, 989-993. http://dx.doi.org/10.1007/BF02236687

Beck, D.E. (1998) Haemorrhoidal Disease. In: Beck, D.E. and Wexner, S.D., Eds., Fundamentals of Anorectal Surgery, 2nd Edition, WB Saunders, London, 237-253.

Cleator, I.G.M. and Cleator, M.M. (2005) The Cleator Clinic. On the Web: Banding Haemorrhoids Using the O’Regan Disposable Bander.

[7] Bleday, R., Pena, J.P., Rothenberger, D.A., Goldberg, S.M. and Buls, J.G. (1992) Symptomatic Haemorrhoids, Current Incidence and Complications of Operative Therapy. Diseases of the Colon \& Rectum, 35, 477-481. http://dx.doi.org/10.1007/BF02049406

[8] Smith, L.E. (1992) Haemorrhoidectomy with Lasers and Other Contemporary Modalities. Surgical Clinics of North America, 3, 665-679. Schussman, L.C. and Lutz, L.J. (1986) Outpatient Management of Haemorrhoids. Prim Care, 13, 527-541.

[9] Liebach, J.R. and Cerda, J.J. (1991) Haemorrhoids: Modern Treatment Methods. Hospital Medicine, August, 53-68.

[10] Norman, D.A., Newton, R. and Nicholas GV. (1989) Direct Current Electrotherapy of Internal Haemorrhoids: An Effective, Safe and Painless Outpatient Approach. American Journal of Gastroenterology, 84, 482.

Bullock, N. (1997) Impotence after Sclerotherapy of Haemorrhoids: Case Report. BMJ, 314, 419. http://dx.doi.org/10.1136/bmj.314.7078.419

[11] Templeton, J.L., Spence, R.J., Kennedy, T.L., et al. (1989) Comparison of Infra-Red Coagulation and Rubber Band Ligation for $1^{\text {st }}$ and $2^{\text {nd }}$ Degree Haemorrhoids. American Journal of Gastroenterology, 84, 475-481.

[12] Russel, T.R. and Donoghue, J.H. (1985) Haemorrhoidal Banding a Warning. Diseases of the Colon \& Rectum, 28, 291-293. http://dx.doi.org/10.1007/BF02560424

[13] Brisinda, G., Civello, I.M. and Maria, G. (2000) Haemorrhoidectomy: Painful Choice. Lancet, 355, 2253. http://dx.doi.org/10.1016/S0140-6736(05)72752-5

[14] Maria, G., Brisinda, G. and Civello, I.M. (1998) Anoplasty for the Treatment of Anal Stenosis. American Journal of Surgery, 175, 158-160. http://dx.doi.org/10.1016/S0002-9610(97)00266-3

[15] Rowsell, M., Bello, M. and Hemingway, D.M. (2000) Circumferential Mucosectomy (Stapled Haemorrhoidectomy) versus Conventional Haemorrhoidectomy: Randomised Controlled Trial. Lancet, 355, 779-781. http://dx.doi.org/10.1016/S0140-6736(99)06122-X

[16] Mehigan, B.J., Monson, J.R.T. and Heartly, J.E. (2000) Stapling Procedure for Haemorrhoids versus Melligan-Morgan Hsaemorrhoidectomy: Randomised Controlled Trial. Lancet, 355, 782-785. http://dx.doi.org/10.1016/S0140-6736(99)08362-2

[17] Fazio, V.W. (2000) Early Promise of Stapling Technique for Haemorrhoidectomy. Lancet, 355, 768-769. http://dx.doi.org/10.1016/S0140-6736(00)00086-6 
[18] Waker, A.J., Leicester, R.J., Nicolls, R.J. and Mann, C.V. (1990) A Prospective Study of Infra-Red Coagulation, Injection and Rubber Band Ligation in the Treatment of Haemorrhois. International Journal of Colorectal Disease, 5, 113. http://dx.doi.org/10.1007/BF00298482

[19] Johanson, J.F. and Rimm, A. (1992) Optimal Non Surgical Treatment of Haemorrhoids, a Comparative Analysis of Infra-Red Coagulation, Rubber Band Ligation, Injection Scelrotherapy. American Journal of Gastroenterology, 87, 1600-1606.

[20] Zinberg, S.S., Stern, D.H., Furman, D.S. and Witteles, J.M. (1989) A Personal Experience in Comparing the Non Operative Techniques for Treating Internal Haemorrhoids. American Journal of Gastroenterology, 84, 488-492.

[21] MacRae, H.M. and Mcleod, R.S. (1995) Comparison of Haemorrhoidal Treatment Modalities: A Meta-Analysis. Diseases of the Colon \& Rectum, 38, 687-694. http://dx.doi.org/10.1007/BF02048023

[22] Milligan, E.T.C., Morgan, C.N., Jones, L.E. and Officer, R. (1937) Surgical Anatomy of the Anal Canal and Operative Treatments of Haemorrhoids. Lancet, 2, 1119-1124. http://dx.doi.org/10.1016/S0140-6736(00)88465-2 